\title{
Instructional Internships: Improving the Teaching and Learning Experience for Students, Interns, and Faculty
}

\author{
Abby L. Hemmerich ${ }^{1}$, Jerry K. Hoepner ${ }^{2}$, and Vicki M. Samelson ${ }^{3}$
}

\begin{abstract}
Students training for clinical careers must acquire skills for teaching clients, their families, and fellow professionals. Guidelines for training programs in Communication Sciences and Disorders (Speech-Language Pathology), however, do not currently include standards for pedagogy. The aim of this study was to measure changes in undergraduate students' perceptions of teaching and learning following an Instructional Internship experience, where they served as teaching assistants for foundational knowledge courses in the major. Using a qualitative research design, we coded 31 participants' statements from pre-and post-internship essays and identified major themes and sub-themes. Our results indicate that by participating in a teaching experience, students develop a deeper appreciation for the relationships between classroom pedagogy, their own learning, and clinical practice. While this study focuses on a pedagogical experience for undergraduate students in a Communication Sciences and Disorders program, the principles and results are generalizable to other professions that train students to provide clinical and educational services.
\end{abstract}

Keywords: teaching assistants, instructional interns, mentoring, doctoral shortage, undergraduates

\section{Introduction}

In December of 2002, the American Speech-Language-Hearing Association (ASHA) Joint Ad Hoc Committee on the Shortage of PhD Students and Faculty in Communication Sciences and Disorders (CSD) released their report identifying a major shortage of doctoral-trained faculty in CSD programs (ASHA, 2002). This concern is relevant to the training of future clinicians, as well as future researchers. The committee's recommendations included: 1) revising the undergraduate curriculum to increase rigor and exposure to academic careers, and 2) balancing the research and clinical curricula so that students at all levels of professional preparation receive greater exposure to research experiences. These recommendations address a key challenge: students who ultimately pursue a Ph.D. are likely to enter a program which does not systematically build upon their undergraduate and graduate learning experiences, especially if those previous experiences occurred at a comprehensive university. This lack of continuity creates a barrier to pursuing doctoral programs, compounded by financial, geographical, and pedagogical constraints (ASHA, 2002). This paper will focus on the pedagogical aspect.

A shortcoming of the ASHA committee report is that it only identifies the deficits in the undergraduate through master's-level graduate curricula, which are heavily weighted towards preparing clinicians. One recommendation made by the committee was to "revise undergraduate

\footnotetext{
${ }^{1}$ Assistant Professor, Communication Sciences and Disorders, University of Wisconsin-Eu Claire

${ }^{2}$ Associate Professor, Communication Sciences and Disorders, University of Wisconsin-Eu Claire

${ }^{3}$ Assistant Professor, Communication Sciences and Disorders, University of Wisconsin-Eu Claire
} 
curricula to increase the scientific rigor and highlight academic careers as a goal” (p. 6). While there is a mismatch between doctoral programs heavily weighted towards research and undergraduate and master's programs that emphasize clinical preparation, this is not the only barrier. A second barrier relates to the lack of education about pedagogy in undergraduate through doctoral preparation (Green, 2010; Harland, 2001). Since pedagogy is essential in both clinical and academic practice, it seems as though it should be a more intentional component of the curriculum at all levels of professional preparation. Faculty at the University of Wisconsin-Eau Claire sought to fulfill this need by creating the Instructional Internship program, to introduce undergraduate students to careers in academia, as well as prepare them to be lifelong teachers in a clinical or academic setting.

A second recommendation of the ASHA committee was to balance the relative proportion of research and clinical content across all levels of professional preparation. Comprehensive universities, like the University of Wisconsin-Eau Claire, focus on clinical education, developing students to be practicing clinicians. Research institutions are heavily focused on research and producing future faculty, leading to a disconnect between these two models of training. Another short-coming of the proposed solutions was a reliance on doctoral training programs as the place to address these curricular concerns. The committee states: "Although there are more than 300 academic programs in the nation, only 62 of them prepare PhDs and fewer than 20 of those prepare the vast majority of future faculty members in the discipline. In fact, data from the Joint Ad Hoc Committee's survey indicate that just 11 programs account for $58 \%$ of the currently enrolled $\mathrm{PhD}$ students" (ASHA, 2002; p. 7). This places the responsibility for preparing future faculty solely on a few research institutions. In reality, it is also the responsibility of non-PhD granting programs to prepare clinicians, teachers, and researchers, so they can enter a doctoral program prepared not only for the rigor of the research, but also the teaching aspects of the profession.

It should be noted that another element involved in addressing the lack of continuity between master's-level and doctoral programs is providing opportunities for student-faculty research experiences at the undergraduate and master's levels. Fostering scholarly inquiry is essential for training future clinicians, teachers, and researchers (Harland, 2001). This curricular outcome, though crucial to encouraging post-graduate education, is not within the scope of the present investigation.

If one of the strategic outcomes for encouraging post-graduate education is highlighting academic careers, pedagogical instruction must be a priority. Currently no ASHA Knowledge and Skills Assessment (KASA) standards exist for pedagogy. Many doctoral programs offer coursework in pedagogy, but these are not often discipline-specific courses. Most undergraduate students in CSD receive limited exposure to pedagogy from Education Studies (teacher preparation) programs. Pedagogies in teacher preparation programs (e.g., Reading Methods) are more narrow in scope than those of CSD programs, which prepare students for interactions across the lifespan and a variety of settings (birth-to-three, pediatric medical settings, schools, private clinics, acute-medical, rehabilitation, long-term care, and homecare settings). While most CSD programs likely provide incidental and informal learning opportunities regarding pedagogy, a direct and more intentional curriculum may be warranted at the undergraduate level and should include discipline-specific pedagogies. 


\section{Teaching in Speech-Language Pathology and Audiology}

Professionals working in the area of speech-language pathology and audiology, across lifespan and settings, are constantly teaching. They teach clients and stakeholders about normal and disordered communication, as well as ways to facilitate improved communication. They teach other professionals about communication disorders and how to identify those in need of assessment. They teach student externs and clinical fellows under their supervision for a clinical experience.

Many informal models exist to learn about teaching in undergraduate, graduate, and postgraduate settings. Unfortunately, those experiences and learner outcomes vary greatly across individuals. For example, student clinicians experience mentorship from clinical supervisors and provide mentorship to co-clinicians and undergraduate observers. While mentorship experiences indirectly shape teaching approaches, specific goals or outcomes are frequently neglected. One potential way to address teaching pedagogy is through guided teaching experiences. In many CSD programs, teaching assistantships have been used to provide this guided learning at the doctoral level, while other disciplines utilize teaching assistantships at the undergraduate or master's levels.

Guided teaching experiences occur within a teaching context (Shannon, Twale, \& Moore, 1998). Following a Vygotskian principle of apprenticeship within genuine contexts, learners experience real problems rather than hypothetical descriptions of problems. Discussions of potential hypothetical permutations does not yield transfer of knowledge to practice (Detterman, 1993; Singley \& Anderson, 1989). Baldwin and Ford (1988) found that only 10\% of off-job training transfers to on-job performance. In order to transfer declarative knowledge to in-themoment problems, one must have adequate declarative knowledge and guided opportunities to apply this knowledge in the moment (Cici \& Ruiz, 1993). That is what guided teaching assistantships accomplish.

\section{Previous Research Related to Undergraduate Teaching Assistants}

Many universities use undergraduate teaching assistants to help facilitate interactive classroom environments within large classes (Adler, 1993; Anderson-Darling \& Earhart, 1990; Fingerson \& Culley, 2001; Froelich, Duckworth, \& Stephenson, 2005; Gaia, Corts, Tatum, \& Allen, 2003; Socha, 1998). Undergraduate teaching assistants can serve in multiple roles, including 1) course-specific mentor, providing feedback and scaffolding of the acquisition of content knowledge; 2) instructional assistant, who aids in planning and facilitating activities; and 3) peeradvocate, to bridge the gap between students in the course and the instructor.

Use of undergraduates as teaching assistants improves the experience and performance of all stakeholders in the course: students, the teaching assistants, and the course instructor (Adler, 1993; Fingerson \& Culley, 2001; Gaia, Corts, Tatum, \& Allen, 2003; Socha, 1998; Wallace, 1974). Students benefit because the teaching assistants are perceived as more available and more approachable than the instructor, given similar age and student-status (Fingerson \& Culley, 2001; Harland, 2001; Mazuka, 2009; Wallace, 1974). Undergraduate teaching assistants are uniquely positioned to bridge this gap between students and instructor by providing mentorship, assistance, and feedback while acting as an intermediary for instructional planning (Anderson-Darling \& Earhart, 1990; Birch \& Morgan, 2005; Gaia, Corts, Tatum, \& Allen, 2003; Peterson, 1990; Yang, 2008). The teaching assistants benefit from the experience in a myriad of ways: a) they develop 
better content-specific knowledge through repeated exposure and explaining concepts to others (Adler, 1993; Fingerson \& Culley, 2001); b) they obtain experience implementing pedagogy and course logistics (Adler, 1993; Anderson-Darling \& Earhart, 1990; Fingerson \& Culley, 2001; Froelich, Duckworth, \& Stephenson, 2005; Gaia, Corts, Tatum, \& Allen, 2003; Socha, 1998); c) they develop an appreciation for the investment involved in facilitating student learning; and d) they increase pedagogical knowledge through faculty and peer mentoring (Adler, 1993; AndersonDarling \& Earhart, 1990; Fingerson \& Culley, 2001). They also begin to recognize the diversity of student learning styles, which can lead to a better understanding of their own learning (Adler, 1993; Fingerson \& Culley, 2001; Wallace, 1974). An undergraduate teaching assistantship may prompt some students to continue their studies and earn advanced degrees in their fields (Adler, 1993; Socha, 1998). While evidence for the value of undergraduate teaching assistants exists in other disciplines, no such evidence is available in communication sciences and disorders. The purpose of this study was to document the outcomes of a mentored undergraduate teaching experience in the field of communication sciences and disorders. To address this purpose, the following questions were explored:

1) What do undergraduate instructional interns gain from a teaching experience, as it applies to clinical/professional practice and academics?

2) Does a teaching experience increase interest in teaching careers?

\section{Methods}

\section{Program Background}

The Instructional Internship program at the University of Wisconsin-Eau Claire is designed to provide undergraduate students with an experience in teaching and was developed in response to the ASHA initiative to increase student recruitment into Ph.D. programs (ASHA, 2002). The experience provides students a glimpse into the daily life of a faculty member, including opportunities for teaching and mentoring fellow students. The role of an instructional intern (II) is similar to that of the teaching assistants described previously. S/he is responsible for assisting the course instructor with daily classroom logistics (e.g., taking attendance, writing notes on the board), maintaining aspects of online course content (e.g., entering grades, posting information for students), and mentoring students in a variety of ways. Mentoring includes leading review sessions prior to exams, providing formative feedback on assignments and papers, and facilitating face-toface and online small group discussions. Students who have earned an A- or better in a particular course are eligible to apply for an instructional internship. Qualified applicants are then matched with specific courses and instructors.

In the initial program development, instructors trained and supervised their own IIs. Expectations across instructors were inconsistent and interns from different courses had minimal opportunities for collaboration. Furthermore, there was no documentation of the interns' outcomes. Programmatic changes, beginning in the fall of 2012, implemented a unified syllabus specifying roles and responsibilities for the intern and the instructor-mentor. This more purposeful approach clarified requirements and expected outcomes for the II experience. Interns completed a group training session, emphasizing course management and pedagogy. They also established a network 
of fellow interns through online discussion forums and a mid-semester meeting, where they shared ideas, as well as successes and challenges with teaching. Instructor-mentors continued to meet with their course-specific interns on a regular basis.

\section{Participants}

Thirty-one CSD students, enrolled in the Instructional Internship program during the fall 2012 semester, were recruited for the study. Interns were not required to participate in the study to complete their instructional internship experience; however, all interns chose to participate and provided informed consent. A summary of characteristics of the instructional interns is provided in Table 1.

Table 1.

Classification and experience characteristics of instructional interns.

\begin{tabular}{cl}
\hline \multirow{2}{*}{ Grade level } & Fall 2012 \\
& $\mathrm{~N}=31$ \\
\hline Senior & 24 \\
Junior & 7 \\
Sophomore & 0 \\
Freshman & 0 \\
\hline Number with previous II experience & 12 \\
\hline
\end{tabular}

Note. Although a number of students had previously completed an instructional internship experience, data remained consistent even when those with previous experience were removed from the analysis. Therefore, all interns, regardless of whether they had previously completed an experience, were included in the analysis.

\section{Procedures}

Baseline Preflection Essays. Before beginning his/her internship experience, each intern completed a "preflection" essay. The essay addressed three major points: a) reasons for choosing to have an instructional internship experience, b) learning expectations, and c) personal skills and attributes to facilitate student learning. Prompts were broad enough to allow flexibility in intern responses.

Training Procedures. Interns participated in one 90-minute session that addressed roles and responsibilities, course-management strategies, and pedagogy. Course management instruction included a review of course-management software, as well as techniques for managing group interactions in online and face-to-face contexts. Background readings in pedagogical approaches were also provided, with an opportunity for discussion of the application of these approaches.

At mid-semester, interns participated in a group meeting to discuss their teaching experiences to date. The interns shared ideas, challenges, and personal learning insights. Faculty 
were present to initiate discussions, but played a limited role in the actual conversation. Although a rich discussion occurred, these data were not included in the current analysis.

An online discussion forum was also open throughout the semester to all instructional interns. Interns used this forum to share questions, suggestions, and occasionally vent their frustrations. Data from the online discussions were not included in the current analysis.

Reflection Essays. After completing the experience, interns submitted a "postflection" essay. The essay addressed two major points: a) personal gains and learning outcomes, and b) changes to the intern's perspective as a learner and teacher. Prompts were broad enough to allow flexibility in intern responses.

\section{Data Analysis}

All preflection and postflection essays were de-identified. Responses were then manually coded using non-hierarchical, open and axial coding (Strauss \& Corbin, 1990) to identify major themes. This process began with each author reviewing $1 / 3$ of the essays to determine potential conceptual labels. All three authors then met to discuss these labels for the pre-flection and postflection essays. Next, the first author identified statement boundaries within all essays by choosing full statements or segments of statements that relayed a single concept and assigning an initial theme/category (open coding) based loosely on the conceptual labels identified. The remaining authors independently reviewed the segmented essays and initial themes/categories assigned to each statement by the first author. All three authors then met to review and compare statement boundaries and theme/category codes. The authors negotiated consensus on each statement and theme (axial coding) by grouping related concepts into categories and choosing a name for those categories. Note that occasionally boundaries or themes assigned to a statement were renegotiated as a part of this iterative process. Some statements were assigned two themes, in recognition that two ideas were sometimes nestled in the same immediate context. Efforts were made to divide text into non-overlapping statements but this was not always possible, so two codes were assigned. While hierarchical organization was not imposed during coding, a distinct order emerged as themes were negotiated, resulting in an overall structure of themes and sub-themes. Following consensus coding, the number of statements within each theme was tabulated as well as the number of participants making a statement within each theme.

\section{Preflection Essays}

\section{Results}

Initial coding of preflection essays identified a total of 354 codes that were assigned to 301 statements (53 statements were double-coded). Coders reached consensus on six major themes (desire to teach/help others, building relationships, personal skills and attributes, leadership/mentoring, knowledge, and pedagogy), with two of these having multiple sub-themes. The percentage of statements within each major theme from the preflection essays is presented in Figure 1. Exemplars were chosen from a variety of essays to illustrate each theme (refer to Appendix A). The percentage of participants who made at least one statement within each theme is presented in Figure 2. In both figures, the themes are presented in order of hierarchical complexity, from least- to most-related to pedagogical principles. 


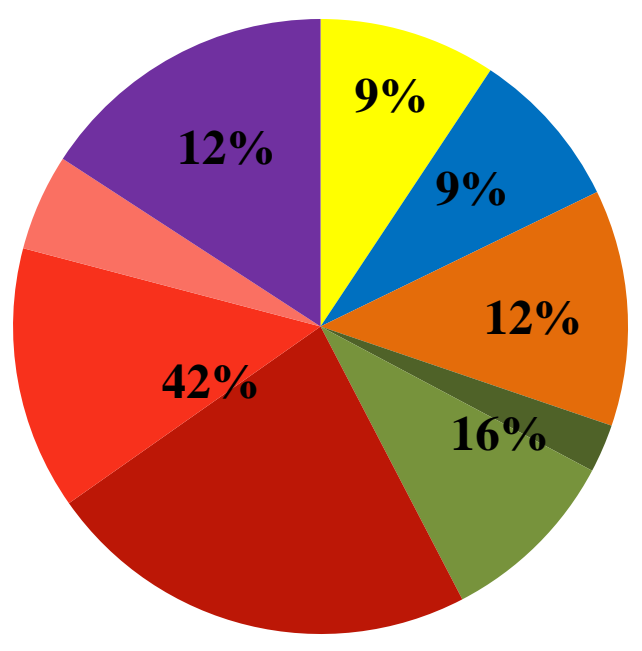

Like teaching/helping others

- Relationships

- Personal skills \& attributes

- Leadership

- Mentoring

- Existing knowledge

- Growing knowledge

- Applying/Sharing knowledge

- Pedagogical methods and approach

Figure 1. Themes and subthemes from pre-flection essays.

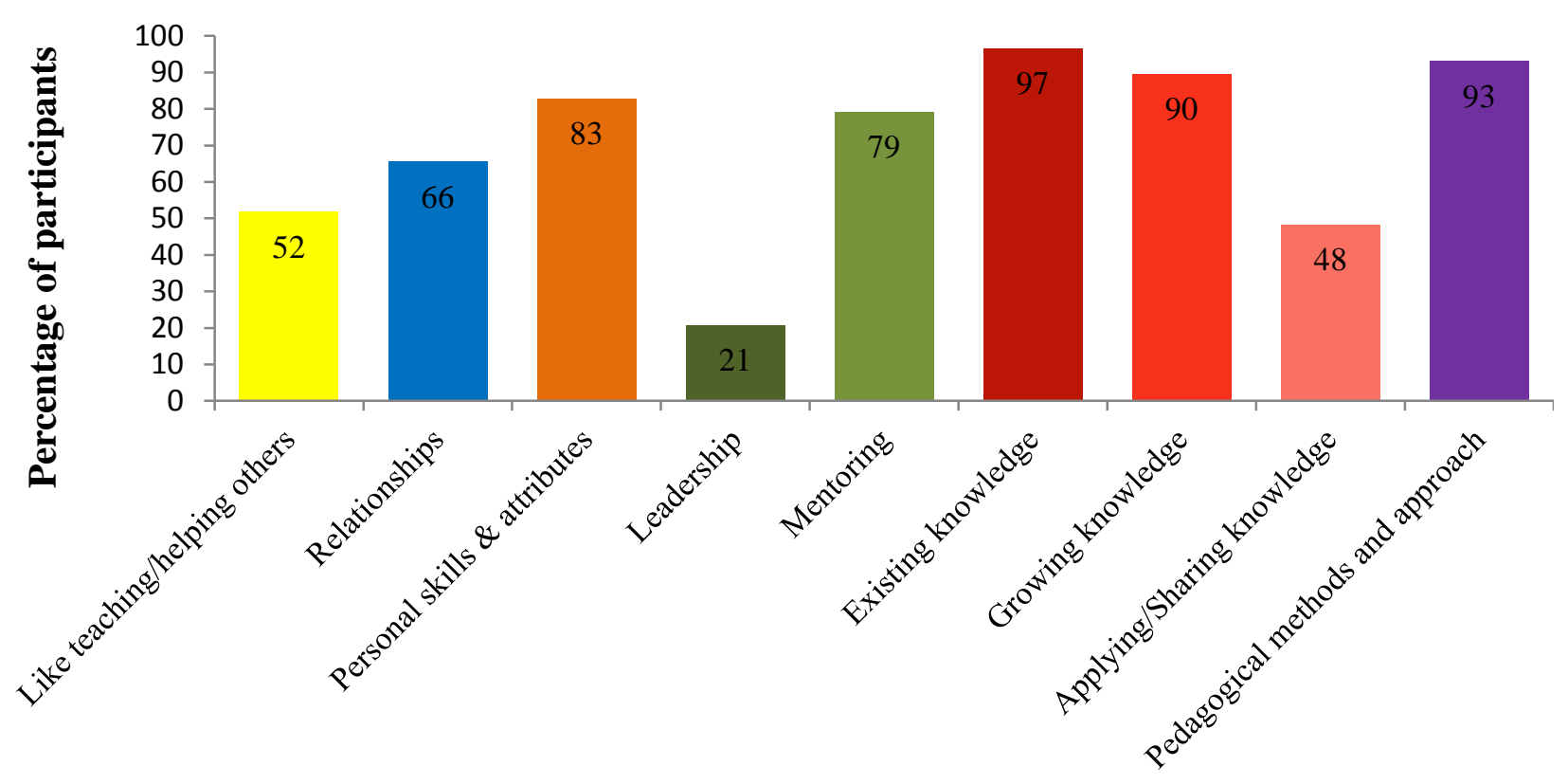

Figure 2. Percentage of participants with at least one statement in each category for preflections. 


\section{Preflection Themes and Sub-themes}

A report of the six themes and subthemes follows, including summative descriptions and select exemplars. Multiple exemplars are available in Appendix A. Themes are reviewed in order of hierarchical complexity, from least- to most-related to reflection on pedagogy/pedagogical principles.

1. Desire to Teach/Help Others: These statements reflected a desire to serve others or were general expressions of teaching as a valued profession. At this level of reflection, pedagogical applications related to the II experience or extensions to future careers were not made. These thought processes were judged as the least sophisticated and accounted for $9 \%$ of all coded statements (see Figure 1). Over half of the interns made statements in this theme (see Figure 2).

2. Building Relationships: Interns began the experience expecting to build relationships with students, faculty, and fellow interns. A few interns identified the relationship between personal connections and fostering learning (e.g., "I hope to establish a relationship with the students so they feel comfortable coming to me for assistance.”). These ideas accounted for $9 \%$ of all coded statements (see Figure 1). Two thirds of interns identified a desire to work with students (see Figure 2).

3. Personal Skills and Attributes: Interns frequently identified organization, reliability, and serving as a resource to students as critical skills. This theme accounted for $12 \%$ of all codes (see Figure 1). Most interns (83\%) reflected on specific skills they possessed that would help them within the classroom (see Figure 2). This relatively higher percentage can be attributed to the fact that interns were specifically asked to address personal skills and attributes in their preflection essays.

4. Knowledge: Interns anticipated a need to apply knowledge in several manners, including drawing from existing knowledge and extending or applying knowledge (42\% of all coded statements; see Figure 1). These statements followed a hierarchy from existing to applied knowledge.

a. Existing Knowledge: Content-specific interests and knowledge were the focus of this subtheme. Most interns identified pre-existing knowledge as an asset (97\% of all participants; see Figure 2).

b. Growing Knowledge: Many interns recognized that beyond drawing upon preexisting knowledge, they would likely gain deeper personal understanding of content through this experience (90\% of interns; see Figure 2). This included developing more confidence and feeling more capable of accessing that knowledge in the future (e.g., “...so that I will forever know phonetics”). Growing and extending knowledge made up nearly half of the statements coded within this theme.

c. Applying/Sharing Knowledge: A third, more sophisticated subtheme was the expectation that knowledge would be shared or applied in future settings (48\% of interns; see figure 2). Clinical connections addressed counseling and teaching future clients and families. Professional applications included extensions to collegial inservices and everyday information exchange. Personal relevance included fostering learning in self and others. 
5. Leadership/Mentoring: Interns aspired to become better leaders and mentor students (12\% of all coded statements; see figure 1). Two subthemes emerged: a vague reference to leadership and a more applied reference to mentoring.

a. Leadership: Interns described a desire to become a better leader, with occasional application to future teaching contexts (21\% of interns; see figure 2).

b. Mentoring: Most interns aspired to create positive learning environments and model a passion for learning (80\% of interns; see figure 2). Many were focused on giving back, after being the recipients of mentoring from their instructional interns.

6. Pedagogy: Interns sought to learn rationales for specific pedagogies, techniques to adapt to different learning styles, and strategies to address difficult material (93\% of all interns; see figure 2). Pedagogical statements were the most sophisticated and accounted for $16 \%$ of all coded statements (see figure 1).

\section{Postflection Essays}

Joint review of post-flection essays identified 256 codes from 198 statements (58 statements were double-coded). Five major themes emerged, including teaching, learning, future applications, personal benefits, and challenges (see Figure 3). Exemplars were chosen from a variety of essays to illustrate each theme (refer to Appendix B). The percentage of participants with statements within each theme is presented in Figure 4.

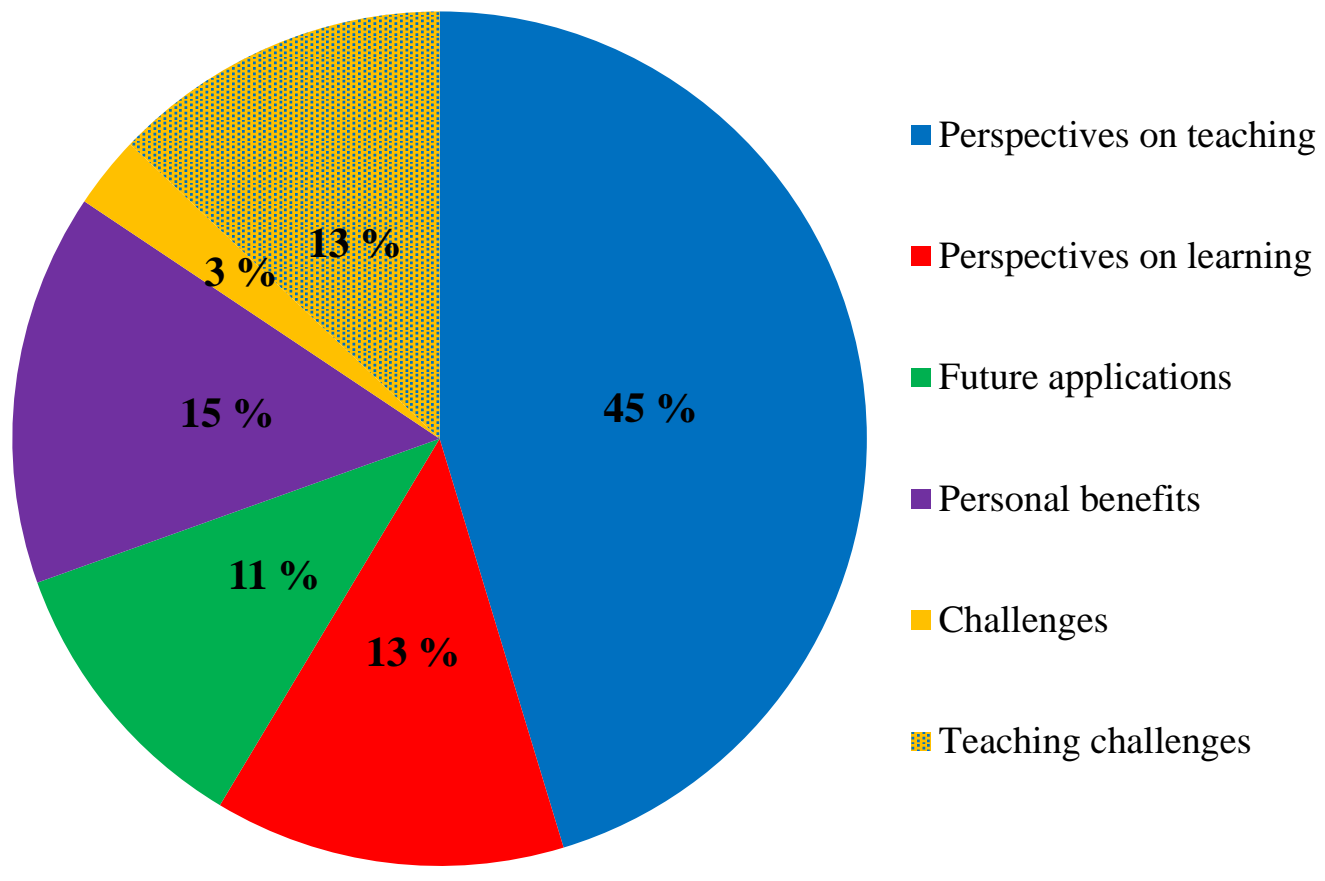

Figure 3. Themes and subthemes from post-flection essays. 


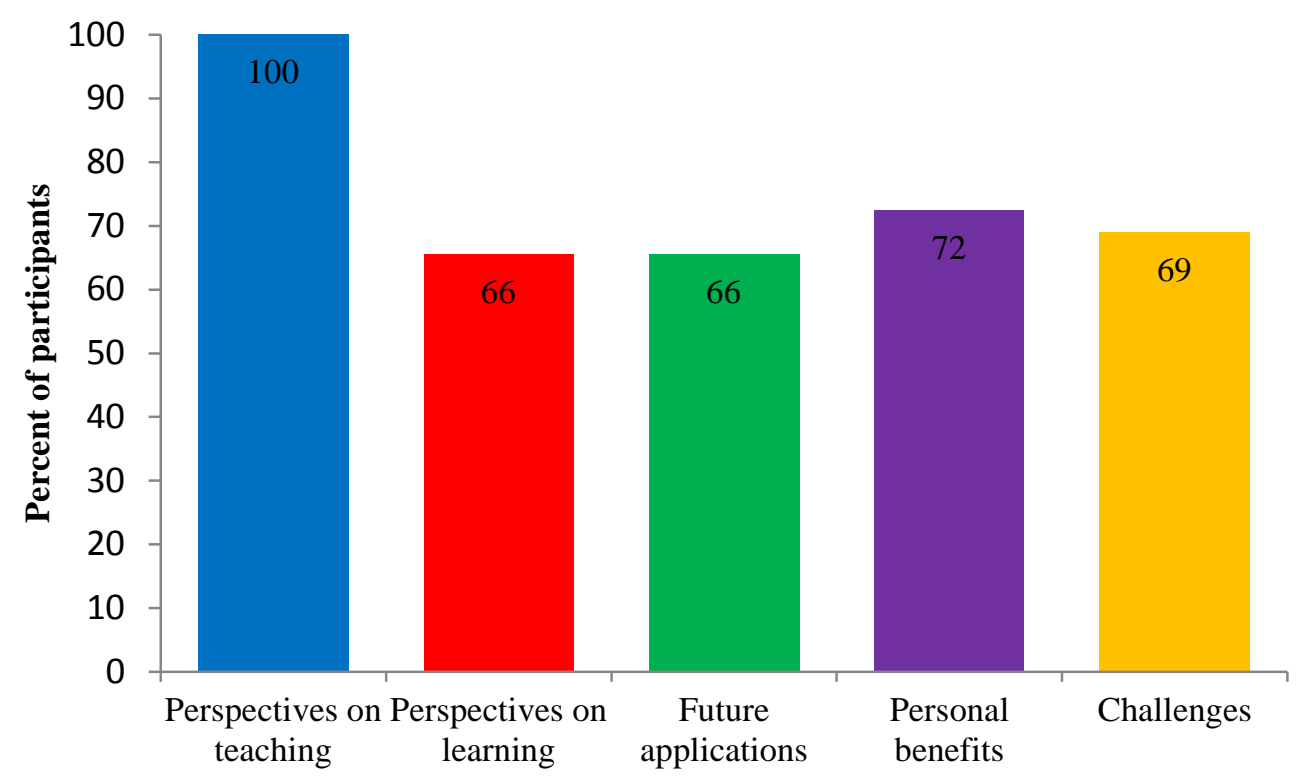

Figure 4. Percentage of participants with at least one statement in each category for postflections.

\section{Postflection Themes and Sub-themes}

A report of the five overall themes and subthemes follows, including summative descriptions of each theme and select exemplars. Multiple exemplars are available in Appendix B.

1. Perspectives on Teaching: All interns reported changes in their teaching perspectives (see Figure 4). This accounted for nearly $45 \%$ of all coded statements (see Figure 3). Multiple interns commented on the need for ongoing personal learning, in order to teach others more effectively. Interns also identified the need to assess what students know, in order to teach at the appropriate level. Recognizing this complexity prompted a better understanding of the investment teachers make in their students' success (e.g., "Without having the opportunity to serve under their supervision, I would not have understood how sincerely both professors want students to learn, grow, and succeed.”). Subsequently, interns identified and implemented strategies for facilitating student engagement (e.g., "I gradually learned to continue to have the students discuss, with myself as the occasional facilitator. Hanging back was not always easy, but I could tell in the students' discussions that it was helping them grapple with the information and learn it better. Once I started doing this more, the questions I was getting from the students were becoming more and more complex, because they were delving deeper on their own!”). This highlighted the importance of flexibility (e.g., "As a teacher I learned that things don't always go the way you plan but if you leave room for flexibility, that can actually turn out to be a good thing.").

2. Perspectives on Learning: Sixty-five percent of the interns discussed changes to their learning perspectives (see Figure 4), which accounted for approximately $13 \%$ of all coded statements (see Figure 3). Interns identified how they would change their own behavior, by reflecting on taking responsibility for their own learning (e.g., “...students play just as Journal of the Scholarship of Teaching and Learning, Vol. 15, No. 3, June, 2015. 
large of a role in the classroom as the instructor"). They also gained an understanding of rationales for specific teaching approaches (e.g., "I didn’t like when a teacher would answer my question with another question. After teaching, I have a better understanding of the critical thinking skills that teachers are trying to develop in their students by answering a question with a question").

3. Applications to Future Career: Sixty-six percent of interns described applications to fellow students and future clients, which accounted for approximately $11 \%$ of codes (see figure $3)$.

a. Fellow students: Several interns reflected on how they would "pay it forward" by giving back to the department, specifically underclassmen. This included serving as a resource to support students in learning course-specific material, commitment to developing future professionals, and giving back the mentorship they received from upper-classmen.

b. Future clients: Interns identified potential applications of newly acquired skills to their future interactions with clients, families, and colleagues. Most recognized the pertinence of teaching to client education, counseling, training use of therapeutic interventions, and interprofessional collaboration. Some even made extensions to how they might impact client quality of life (e.g., "I know I can make a difference in the success of someone's life...it's not just a career, it's making a difference in people's lives, which is really what's important”).

4. Personal Benefits: Nearly three-quarters of interns identified personal gains (see figure 4), accounting for $15 \%$ of all coded statements (see figure 3). Interns often solidified career decisions based on a second exposure to the content. Skills enhanced through the experience included leadership, public speaking, and critical thinking. Furthermore, they realized the importance of being a proactive student to solidify their own content knowledge.

5. Challenges: Instructional challenges accounted for $16 \%$ of all coded statements (see figure 3 ). Most of these were pedagogical in nature, rather than operational logistics (83\% were double-coded as teaching and challenges). Interns frequently identified challenges associated with fostering intrinsic motivation among students. This led to a new respect for teachers, by recognizing the effort, planning, and expertise required to be an effective instructor.

The second research question aimed to determine whether experiences in teaching increased interest in teaching careers. Table 2 illustrates the percentage of students discussing their teaching interest within their essays, as well as the specificity of those statements. 
Table 2

Statements addressing research question two: Does a teaching experience increase interest in teaching careers?

\begin{tabular}{|c|c|c|}
\hline & \% students & Specificity of teaching interests \\
\hline Pre-experience interest in teaching & $14 \%(4 / 29)$ & $\begin{array}{l}\text { Exploration of teaching as a } \\
\text { career }\end{array}$ \\
\hline $\begin{array}{l}\text { Post-experience interest in } \\
\text { teaching }\end{array}$ & $14 \%(4 / 29)$ & $\begin{array}{l}\text { Specific statements of intentions } \\
\text { to pursue a teaching career }\end{array}$ \\
\hline $\begin{array}{l}\text { Post-experience realization that } \\
\text { teaching was not their interest }\end{array}$ & $3 \%(1 / 29)$ & $\begin{array}{l}\text { Specific statement of intention } \\
\text { not to pursue a teaching career }\end{array}$ \\
\hline
\end{tabular}

Prior to internships, 52\% of interns expressed an interest in teaching and/or helping others. The majority of these statements were non-specific and focused on fostering student success ("wanting to give back"). None of these students identified a specific desire or plan to pursue a teaching position and/or doctoral degree; however; four of 29 students identified the internship experience as an opportunity to explore potential interest in teaching ("A nice foot in the door to see if I am interested in teaching” and “...experience teaching at the collegiate level.”). Following the internship, 66\% of interns described applications of teaching in their future careers. These interns were more specific in their applications and four out of 29 interns identified a desire or plan to pursue a teaching position and/or doctoral degree ("Being an II has gotten me really excited about teaching, and has further inspired me to pursue not only an AuD but also a PhD." and "From this experience I feel that I have a heightened interest to one day pursue a career in teaching at the collegiate level." and "I plan to apply for a teaching assistantship in graduate school because of this experience.”). One individual determined that teaching was not the career for her based on her experiences as an intern. The remaining individuals in that 66\% were making clinical teaching applications ("Looking back on it, many of the teaching strategies and goals are the same for teaching and for therapy. Therefore as a speech-language pathologist, it is important to have the skills required to be a good teacher, because that is what you are essentially doing.”).

\section{Discussion}

The 2002 ASHA Initiative to increase interest in academic careers was the impetus for developing our Instructional Internship program. However, the program has developed into much more than a way to address the PhD shortage. It creates opportunities to acquire critical thinking and fosters the desire for teaching. By becoming better teachers and learners, students recognize the relationship between classroom pedagogy, student learning, and clinical practice. The program has proven beneficial for the instructional interns, the students enrolled in the courses, and the instructors. 


\section{Implications for Instructional Interns}

Students enrolled in instructional internships made significant advances in a variety of domains. At the outset of their experience, interns hoped to increase their content knowledge and develop leadership skills. Many of the goals and expectations were focused on their own learning; some were focused loosely on paying it forward, and a few focused on pedagogy. As they completed their experiences, growth was evident in their postflections. While some themes appeared in both pre- and postflections, the depth of knowledge and understanding changed. Interns identified growth in their content knowledge, but also highlighted increased understanding of how to teach and how to learn. In this way, they recognized that teaching others is an effective way to accomplish their own learning goals, which motivated them to become better teachers (e.g., "Seeing the importance of these aspects while teaching class gave me a greater understanding of how to be a better student in other classes. It taught me that students play just as large of a role in the classroom as the instructor.”). These findings were similar to previous studies (Adler, 1993; Fingerson \& Culley, 2001; Gaia, Corts, Tatum, \& Allen, 2003; Harland, 2001; Shannon, Twale, \& Moore, 1998). Goals related to paying-it-forward were vague in preflections (e.g., "I could be an active participant in another person's education.”) but postflections identified specific strategies to foster learning and give back (e.g., "I can apply what I have learned in my experience as an II to my future experiences in the clinic. I will be teaching new techniques and strategies to clients, just as I have taught new information to students in Phonetics.”). Interns moved from limited conceptualizations of teaching towards adopting specific pedagogies and applications to their future careers as clinicians, counselors, supervisors, or instructors in academic settings.

Interns recognized that opportunities to practice effective communication and teaching strategies have clear applications for future clinical experiences. The connection between teaching in the classroom and teaching as a clinician was clear in the postflection essays of many instructional interns. Students who were concurrently enrolled in the instructional internship and the undergraduate clinical experience were particularly cognizant of this connection, and discussed the parallels in their essays (e.g., "This overlaps with my experience as an undergraduate clinician this semester, because essentially I was teaching a skill during my therapy sessions. The difference between my clinic and II experiences was the material I was teaching.”). By teaching the interns about pedagogy, we have provided direct instruction in an area which is usually addressed indirectly and inconsistently during clinical experiences. The internship curriculum introduced a model of evidence-based practice through readings and discussions about teaching. Intentional instruction in pedagogy, drawn from relevant research, allows students to make extensions to evidence-based clinical practices.

Research question 2: Did the experience influence any interns to pursue an academic career? In pre-experience essays, four interns indicated this as an opportunity to explore teaching as a career. In the post-experience essays, four different interns discussed teaching as a long-term goal. Long-term outcome data are needed to track student follow-through. The intent of several students to pursue doctoral degrees is consistent with other reports of similar programs (Adler, 1993; Fingerson \& Culley, 2001; Socha, 1998). Short-term data suggest that instructional internships foster an awareness of teaching as a critical skill for the profession. IIs specifically identified opportunities for teaching clients, families, colleagues, student-externs, and clinical fellows, and expressed interest in clinical instruction at the university level. 


\section{Implications for Students}

Students benefit from the support of instructional interns in their courses. Given the use of problem- and team-based curricular approaches, having additional instructional team members enables each student to have one-on-one interaction on a daily basis (Adler, 1993; Fingerson \& Culley, 2001; Harland, 2001; Wallace, 1974). Because questions are addressed quickly, students move deeper into content discussions. Additional resources promote timely, formative feedback on low-stakes assignments, which allows students to make adjustments to their knowledge prior to summative assessments (e.g., "If I were in the students' shoes, I would want speedy and trustworthy responses, so I tried to provide that communication for them.”).

The ability of interns to serve as a mediator between instructor and student is arguably their most important impact because undergraduate students may feel uncomfortable asking questions or approaching an instructor. Similar to previous research, interns serve as a more approachable version of the instructor, answering questions and relaying concerns to the professors (Adler, 1993; Fingerson \& Culley, 2001; Harland, 2001; Muzaka, 2009; Wallace, 1974). Fifty-two percent of interns reflected approachability as an important characteristic in their pre-experience essays. Specifically, they drew upon their own previous experiences as students and related the importance of connecting with someone other than the professor to address questions and concerns (e.g., "Another important skill as an instructional intern is being approachable. Sometimes, students are not comfortable asking the professor a question in front of the class, so providing students with a secure and supportive way of getting information is critical for an instructional intern.”). Twentyone percent of interns described the positive effect of their approachability in post-experience essays.

\section{Implications for Instructors}

Instructional internships create opportunities for faculty to model effective teaching and learning, by utilizing evidence-based research to support pedagogy (Adler, 1993; AndersonDarling \& Earhart, 1990; Birch \& Morgan, 2005; Froelich, Duckworth, \& Stephenson, 2005; Gaia, Corts, Tatum, \& Allen, 2003; Green, 2010; Shannon, Twale, \& Moore, 1998; Wallace, 1974). Interns see the investment instructors make to reach each student, which bolsters job satisfaction and commitment, reflected in the interns statements about instructor dedication to student learning (55\% of the essays included such statements; e.g., "After just these two tasks I completed, I learned the teacher really is doing it all for the student. They do not just make assignments and tasks to make it more difficult for the student, because in reality it just creates a lot more work for the professor.). The extra personnel allows instructors to develop additional learning resources (e.g., videos, discussions, readings, writing feedback, cases) and implement active learning in class. Team-based pedagogies are more effective because there are more people to circulate and provide feedback. By facilitating weekly discussions with interns about pedagogy, instructors may also solidify their rationales and foster input to further refine learning activities.

\section{Does it create more work for us as instructors?}

The initial start-up of this type of programming requires a substantial commitment by all faculty (Socha, 1998; Wallace, 1974). Policies and a syllabus were created to establish clear 
expectations for instructional interns. Training is necessary at the outset of each semester to ensure successful mentoring endeavors. Once established, however, the program seems to lessen the workload for instructors. Instructional interns assist with day-to-day classroom management: maintaining attendance, facilitating team discussions, grading objective assignments, and serving as a communication intermediary for reticent students. Interns also assist with presentation of content by responding to student emails, leading review sessions, and providing additional resources or explanations as needed (e.g. "After working with several instructional interns in the past, I have an idea of how I want to effectively serve others through the experience. This includes being knowledgeable about the content being discussed, being available outside of class for any questions or help students need, being a resource for students, and just being available for teacher as one they know they can rely on.”). During in-class activities, having multiple instructional interns within the classroom extends the reach of the instructor (Adler, 1993; Fingerson \& Culley, 2001; Harland, 2001; Muzaka, 2009; Wallace, 1974), making small group learning more effective.

The effectiveness of an instructional intern is only as good as the mentoring s/he receives. One challenge in maintaining a program is consistency across instructor-mentors. Eleven faculty members at the University of Wisconsin-Eau Claire served as mentors for one or more instructional interns in their courses. Each mentor has a different pedagogical background and different teaching style. Although they share similar teaching approaches, variability exists in the specific roles of interns in each course. In order to achieve the best possible outcomes for each intern, mentoring needs to be consistent and intentional across faculty members (AndersonDarling \& Earhart, 1990; Birch \& Morgan, 2005; Froelich, Duckworth, \& Stephenson, 2005).

\section{Does this Encourage Students to Re-conceptualize Teaching?}

The instructional internship program has encouraged students to consider careers in academia. Because there is a disconnect between master's-level clinical training programs and doctoral-level research training programs, exposing undergraduate students to aspects of both pedagogy and research more intentionally connects clinic, teaching, and research.

Masters programs are predominantly designed to prepare clinicians to implement a variety of assessment and intervention techniques. Often, the instruction in how to teach these techniques to clients and families is implied rather than explicit. Our preliminary data on pedagogical development suggests that instructional internships will produce students who are better prepared to reflect on the learning process, teach their clients and colleagues, and make connections between these roles (e.g. “... as a professional working with a client, family members, or co-workers, I will always be in a position to teach people.”. Students who have experienced both components of the teaching-learning process are uniquely prepared for a supervisory role with clinical externs, clinical fellows, or at a teaching institution.

Explicit training in pedagogical methods is not consistently or intentionally integrated into CSD curricula. ASHA expects clinicians to demonstrate competency in training and support of family members and other communication partners of individuals with speech, voice, language, and other communication disorders. Further, clinicians must be competent to train and supervise support personnel. Mechanisms for achieving these two competencies are vague. ASHA defers to state standards for licensing and teacher certification; however, this only applies to school settings. There are no comparable standards for clinicians in medical and rehabilitation settings. Although ASHA is more specific about supervision competencies (refer to ASHA's 1985 position 
statement), the mechanism for achieving those competencies remains vague (e.g., continuing education courses).

Training in teaching typically occurs at the undergraduate level within the context of education or psychology courses. Master's programs in CSD have little or no emphasis on training in pedagogy, beyond counseling and information dissemination to clients. While we train student clinicians to teach techniques and use consumer-friendly language, we do not always support the approach with evidence. Doctoral programs inconsistently address teaching, as the value placed on teaching is highly variable across institutions and mentors.

Consistent with prior research (Adler, 1993; Anderson-Darling \& Earhart, 1990; Shannon, Twale, \& Moore, 1998), our results indicate that classroom teaching experience increases selfefficacy in teaching. Seventeen percent of interns in the current study reported feeling more comfortable after exposure to a teaching role (e.g., "Although I learned the material before, it was difficult at first to clarify concepts students were unfamiliar with. However, I found teaching became easier over the semester. I tweaked how I explained information and tried to connect the material to concepts students could really relate to.”). Moreover, rationale for teaching approaches was clarified and refined through the explicit discussions about pedagogy. In their reflections, interns applied this broadly to their own learning and future clinical endeavors; $24 \%$ of interns specifically described understanding rationales for various pedagogical methods (e.g., "I learned how powerful acquiring knowledge in a group-based method really was.”). This parallels the outcomes by Shannon and colleagues (1998), who noted that experience with teaching makes teaching assistants feel more comfortable but training in pedagogy increases their effectiveness. Interns who pursue a doctoral program should be better prepared to apply best pedagogical practices as a teaching assistant and future faculty member.

By drawing heavily upon pedagogical research, interns see applications of evidence-based outcomes on a daily basis. Mentors guide interns within classroom interactions and weekly planning meetings to make connections between evidence and practice clear. Review of pedagogical research methodology and implementation can also help foster extensions to discipline-specific research content. Harland (2001) found that such inquiry-based approaches allow teaching assistants to develop and apply problem solving skills in both research and teaching contexts. This fills an important void in transferring content knowledge in clinical and academic contexts. It is often assumed that knowledge of discipline-specific content is adequate for effective teaching. Interns reflected that being effective in the classroom required much more than knowledge of the content (66\% of essays); they specifically discussed techniques to facilitate understanding of content (e.g. "I also learned how to be a better communicator throughout this experience. Simply telling a student the answer does not help her become a better student, but talking around the answer and giving a better background on the question will help her succeed.”). Nyquist (1991, as cited in Tulane \& Beckert, 2011) identified the problem with this misconception: if the approach to conveying content knowledge matters, pedagogy should be an intentional element of the curriculum. Because faculty and peer mentoring helps teaching assistants to develop pedagogical knowledge (Adler, 1993; Anderson-Darling \& Earhart, 1990; Birch \& Morgan, 2005; Froelich, Duckworth, \& Stephenson, 2005; Gaia, Corts, Tatum, \& Allen, 2003; Green, 2010; Shannon, Twale, \& Moore, 1998; Wallace, 1974), it should serve as a requisite component of that curriculum.

Working collaboratively with faculty on a daily basis and discussing the aspects of a career in academia may reduce the intimidation of a research career and increase the likelihood that some 
of these students will seek advanced degrees (Fingerson \& Culley, 2001). Of those participating in this study, one has committed to a combination AuD/PhD graduate program; others have expressed a career goal of pursuing an advanced degree after they have finished their clinical training. All instructional interns have seen both the highs and lows of a faculty career. Through weekly discussions, they witness the deep investment the faculty members make in their students. They have been included in the discussions of student success, where instructors celebrate student achievement (e.g. "Seeing students learn and being at the forefront of this process was delightful. Seeing my students succeed and being there when "the light bulb when off" was very exciting and gave me a sense of pride.”). They have also been included in challenging discussions of students who are cheating, students who are not motivated, or students experiencing life events that impact their performance in the classroom (e.g. "Throughout this experience I have gained an even stronger respect and understanding for my professors. I always knew there were a lot of components to teaching but I had absolutely no idea how many different components that a professor faces on a daily basis. Not only do the professors have to organize and plan out the class but they also need to stay highly organized with different needs of each student.”). Interns feel the frustration or empathy expressed by the faculty member and learn to handle challenging situations (e.g. "Furthermore, when they struggled, I felt that struggle as well, and tried my best to re-word, re-teach, and re-structure the material in order to most effectively help them as needed.”). Interns also see the workload involved in an academic career. They are quick to note that this is not a 9-5 job, and that there is much more happening "behind the scenes" than they ever thought possible (e.g. "As a learner I’ve realized that professors and instructional interns are very busy and they do everything they can to get to your emails and questions and provide office hours as well as they can, but it's not that easy. As a learner, I've always been almost obsessed with knowing my grades immediately, especially when it comes to exams. I've learned to ease up and keep in mind that everyone is doing all they can.”). These real-world experiences should help students be realistic about what a career in academia would entail.

\section{Limitations and Future Directions}

The initial impetus for Instructional Internships was to provide a mentored teaching experience for students, which may encourage them to pursue doctoral education or a career in an academic context. As the program developed, goals expanded to include training for teaching in clinical contexts. Further, we have become interested in the reciprocal benefits of instructional interns on students, faculty, and instructional intern learning. The current study examined this program through the lens of the instructional interns, recognizing their impact on student learning and implementation of faculty pedagogy. In addressing our original goal of encouraging pursuit of Ph.D. training, the ultimate test of our Instructional Internship program will be to measure on a long-term basis whether or not more of our undergraduates pursue doctoral degrees.

In addressing implications to clinical practice, future research can focus on measuring the generalization of pedagogical knowledge and skills to students' clinical relationships with clients, families, and peer-clinicians. To address reciprocal benefits to students, faculty, and instructional interns, the perceptions of these groups should be measured more directly. Future studies may address the impact of instructional interns on student and faculty outcomes through surveys or interviews. While the present study examined the immediate implications of a guided teaching experience on the instructional interns, further studies are needed to measure the reciprocal and 
individual effects on all those involved (i.e., faculty, students, and interns) in a contextual and longitudinal manner.

\section{Conclusion}

The instructional internship is a unique opportunity for undergraduate students to get a glimpse of what it is like to work in academia. The experience provides guided apprenticeship in teaching, hands-on practice with immediate feedback, and refined content knowledge. Specifically, this study demonstrated an increased value for instructional techniques and pedagogies, applications to or extensions of their own content learning, extensions to everyday practice (i.e., in the CSD professions, extensions to clinical work), and increased interest in pursuit of an academic career for some students. While data from the current study were specific to a Communication Sciences and Disorders curriculum, outcomes and principles could be cautiously applied to other disciplines. Evidence for this generalization is based in the consistency of our outcomes with those of teaching assistants described in previous research (Adler, 1993; AndersonDarling \& Earhart, 1990; Birch \& Morgan, 2005; Fingerson \& Culley, 2001; Froelich, Duckworth, \& Stephenson, 2005; Gaia, Corts, Tatum, \& Allen, 2003; Green, 2010; Harland, 2001; Shannon, Twale, \& Moore, 1998; Wallace, 1974). The benefits extend to students in the course and the instructor, by helping to broaden the reach of the instructional team. It is our hope that programs such as this will encourage students to consider a scholarly career. Regardless of whether they pursue a doctoral degree, however, they are now uniquely trained to be successful in any teaching situation, with patients and their families, with clinicians under their supervision, or with colleagues.

\section{Acknowledgments}

The University of Wisconsin-Eau Claire Communication Sciences and Disorders departmental faculty and staff, all instructional interns who participated in this study, and the College of Education and Human Sciences for funding.

\section{Appendices}

Appendix A. Preflection Themes and Sub-themes

Exemplars presented here were chosen from a variety of essays to illustrate each theme.

\section{Theme 1: Desire to teach and/or help others}

"I feel that I would be caring and compassionate towards the students because I took this course just last year and I still am a student. I know what it's like to be a student and not understand something or be overwhelmed with material, so I can easily relate to how they feel and that makes me want to help.” (participant 8)

Journal of the Scholarship of Teaching and Learning, Vol. 15, No. 3, June, 2015. 
"I have the passion and desire to serve and help others, and a passion for the major and learning more.” (participant 26)

"Another thing I hope to get from this experience is how much or how little I enjoy teaching students and if it is something I would consider doing in the future.” (participant 19)

“Teaching others is empowering and such an under-respected ability.” (participant 24)

"I hope this experience will help me gauge my interest in teaching as a future career." (participant 23)

"I am looking forward to helping the students understand how diverse our major is and how important it is for many different populations.” (participant 15)

\section{Theme 2: Building relationships}

"I look forward to working one-on-one with students and faculty.” (participant 3)

"I am hoping to create closer CSD peer and faculty relationships. It is important to connect with other people who are passionate and are driven in this field.” (participant 4)

"I hope to establish a relationship with the students so they feel comfortable coming to me for assistance.” (participant 25, double-coded with pedagogy)

\section{Theme 3: Personal skills and attributes}

"I see that I am an organized, responsible, and reliable individual who is not afraid to ask questions.” (participant 11)

"I am a very patient person. I do not mind answering many questions...I am also a very dependable individual. I have a strong sense of duty and of my tasks. When others are depending on my work, I cannot put things off until the last minute.” (participant 10)

"Because I took this course online I will be a great resource to students, giving them tips and advice about working in groups online and gaining the most from a less personal interaction with the instructor.” (participant 28)

\section{Theme 4: Knowledge}

\section{Subtheme 1: Existing Knowledge}

"Learning about the bone structures, bodily systems, and muscles was intriguing to me so I was continuously eager to learn more information.” (participant 4) 
"It has been my favorite class within this major up to this point. I like hearing about voice disorders.” (participant 21)

"I know that it is a great way to get more involved in the major and it can help me to retain my knowledge of important concepts and topics.” (participant 27)

\section{Subtheme 2: Growing Knowledge}

"One of my favorite parts of being an instructional intern was the opportunity to solidify knowledge presented in past courses by further exploring the material. CSD courses are challenging and exciting; the opportunity to view them in a different light is invaluable.” (participant 5)

"An instructional internship is also an excellent way to review information and put my own knowledge to the test." (participant 10)

"It's one thing for me to learn a subject, but it's a totally different aspect for me to teach a subject. I need to walk through things out loud in order to remember them, and I also need to hear things a few times. As an II, I hope to be given the chance to do both so that I will forever know Phonetics.” (participant 29)

"I also thought it was important to maintain the knowledge I acquired in order to use it in the future. Consequently, refreshing what I have learned and making more connections with the material will help with the preservation of knowledge.” (participant 30)

\section{Subtheme 3: Applying/Sharing Knowledge}

"Given this opportunity to be an instructional intern, I feel I can take a more active role in my education. I believe I will develop a more thorough understanding of the material by explaining the concepts of the course to other students. Most importantly, the skills to explain certain aspects of the class are skills that I can use in the future when explaining concepts to those who have no background knowledge of what concepts are being addressed." (participant 18, double-coded growing knowledge and application of knowledge)

"People learn at different paces and through various modes. I hope through my instructional internship experience, I will develop a better sense of how people learn in order to effectively teach and learn from others, especially in my future courses and in my career." (participant 30)

"Also, I know this experience will better prepare me for my future as a graduate student as well as in my future career by allowing me to gain insight into teaching and facilitating 
learning. Finally, this experience will create a deeper appreciation for education and all the elements that are not observed as a student.” (participant 20, double-coded with pedagogy)

"I aspire to become a practicing Speech Language Pathologist, which will require me to engage, motivate, and teach my clients. Having an instructional intern experience will provide me with the opportunity to practice these skills and to gain more insights into how to most effectively do so.” (participant 12)

\section{Theme 5: Leadership/Mentoring}

Subtheme 1: Leadership

"I hope to improve my leadership and relational skills through the experience." (participant 26)

"The most important skill I wish to get from this experience is becoming a better leader." (participant 13)

"I have become a leader, which in turn has led me to the interest in becoming an instructor later on in my life.” (participant 1, double-coded with liking teaching)

\section{Subtheme 2: Mentoring}

"I chose to be an instructional intern because I enjoy having leadership roles. I specifically chose the FYE introduction course because I can remember how much I looked up to my instructional interns when I was a freshman. I feel that it is very important to have a positive and easy to approach person as instructional intern and I hope to be that person for the freshman in my class.” (participant 7)

"I have a lot of patience, so I would be willing to help the students with the material." (participant 8)

"I want to be a service to the students to help provide a smooth transition to UWEC. If I am able to answer questions and make them feel more comfortable in the university atmosphere, they may be better able to concentrate and focus on their studies." (participant 2)

"I would like to be an instructional intern that helps change this mindset of students, to help them appreciate this course and to enjoy it. I think it is very valuable for students to see, in addition to the passion shown by the professors, another student having a sincere appreciation for and pleasure in learning.” (participant 12) 


\section{Theme 6: Pedagogy}

"I feel that it can be significantly beneficial to teach content that I have previously learned. Teaching others causes you to think deeply about topics in different ways than you may have originally thought. (participant 11, double-coded as pedagogy and growing knowledge)

"I understand and appreciate the value of providing these additional services for students, and from my experiences going to these meetings, I know what I did and did not like about how they were conducted - this will guide how I plan to conduct my own meetings with students." (participant 12)

"I chose to become an II to gain experience on the other side of the classroom experience. I hope that being an II will help me have a better understand of how and why professors present and teach material they way that they choose to.” (participant 22)

"I'm starting to appreciate many of the activities I completed in my previous coursework and why the professors chose these particular types of activities in given circumstances." (participant 23)

"I have experience working with a variety of classroom styles. I can contribute to student learning as an II because I am able to adapt to many forms of teaching and learning. I realize students have different ways of learning, so I will adjust to each person's needs to provide him or her the information required.” (participant 25, double-coded as pedagogy and personal skills)

"As a student in the CSD program, I have found instructional interns to be a vital component to my learning. They are a helpful resource and can often offer an alternative explanation to course material. They have been role models for me, and I truly appreciate the extra time they put in to help me through difficult concepts and assignments.” (participant 14)

Appendix B. Postflection Themes and Sub-themes

Exemplars presented here were chosen from a variety of essays to illustrate each theme.

\section{Theme 1: Perspectives on teaching}

These reflections included an understanding of teaching as a continuous learning process:

"Also, I feel that as a teacher, you are still learning. Teachers must continue to learn and find different strategies for teaching different topics or for teaching different types of students. " (participant 23) 
"One of the greatest lessons I got from this experience is that learning truly is a continuous process. Even as an II, someone who has demonstrated competence in a certain subject, I found I was constantly learning. This experience taught me it is alright to not have an answer to every question.” (participant 25; double-coded with perspectives on learning)

Other participants focused on specific strategies, skills, or techniques they used while teaching:

"As a teacher, I learned that things don't always go the way you plan, but if you leave room for flexibility, that can actually turn out to be a good thing!” (participant 29)

"I learned to make a PowerPoint students will follow, to lead an activity that is conducive to learning, or to prepare information given in a lecture, educators must have a heightened sense of awareness. They have to recognize what students do and do not know, teach accordingly, present information applicable to the field, revise when needed, and challenge students.” (participant 25)

I learned how to change the way I explain a CSD concept to another individual. I am used to discussing CSD topics with other CSD majors who know the acronyms, jargon, and content that I already know. I had to learn how to break a concept down, explain the acronyms and jargon , and describe the information in a way that the student without CSD exposure could understand.” (participant 2)

"I learned having a little fun during class doesn't take away from the student learning. When they started to see me more as an equal, they became more inclined to answering my questions during group work and asking for clarification of material.” (participant 6)

"Leading a class with the other II's taught me about the dynamics of how a classroom works. Voice and Resonance Disorders is an open discussion based class. Students are encouraged to ask questions, work with group members, and comment on videos shown. To have a productive class, the students need to be actively involved (commenting on a video), curiously ask questions, and participate in group discussions.” (participant 16)

Still others discussed the investment teachers make in their students' success:

"Seeing students learn and being at the forefront of this process was delightful. Seeing my students succeed and being there when "the light bulb went off" was very exciting, and gave me a sense of pride. Furthermore, when they struggled, I felt that struggle as well, and tried my best to re-word, re-teach, and re-structure the material in order to most effectively help them as needed.” (participant 3)

"Without having the opportunity to serve under their supervision, I would not have understood how sincerely both professors want their students to learn, grow, and succeed. Obviously teachers are supposed to want these things for their students, but with each 
Thursday morning meeting, I was continually reassured of the professors' desire to have each and every student succeed.” (participant 4)

"Throughout this experience I have gained an even stronger respect and understanding for my professors. I always knew there were a lot of components to teaching but I had absolutely no idea how many different components that a professor faces on a daily basis. Not only do the professors have to organize and plan out the class but they also have to stay highly organized with different needs of each student." (participant 7, double-coded as a challenge)

"I learned that in a teaching role it is appropriate to set limits on how accessible you are to students and what you offer to do for them. It is important to be available to answer questions, look over rough drafts, meet to review, etc. However, it is equally important to recognize how large a load you can take on as a teacher, and how much dependence you should allow your students to have on you.” (participant 12)

Finally, some participants discussed facilitating student engagement:

"I gradually learned to continue to have the students discuss, with myself as the occasional facilitator. Hanging back was not always easy, but I could tell in the students' discussions that it was helping them grapple with the information and learn it better. Once I started doing this more, the questions I was getting from the students were becoming more and more complex, because they were delving deeper on their own!” (participant 12)

"I also learned new ways to develop relationships with the students in order to make them feel more comfortable asking questions. I was always available before and after class to answer questions, as well as in emails. I discovered that being personable in class and seeming eager to help will make the students more willing to come and ask questions." (participant 13)

\section{Theme 2: Perspectives on Learning}

"Although I relish the opportunity to hear knowledgeable and interesting faculty lecture, I realize the importance of taking responsibility for my own learning and preparing before class, in order to complete group assignments and discussions even more now." (participant 5)

"Although I am still a student, I have learned so much in these four years and I find it difficult to relate to the "freshman minds" and realize how little I knew about this major as a freshman.” (participant 7) 
"Seeing the importance of these aspects while teaching class gave me a greater understanding of how to be a better student in other classes. It taught me that students play just as large of a role in the classroom as the instructor.” (participant 16)

"Overall this experience has made me a better student. I have gained a deeper appreciation for information presented to us as students and how important it is to be a proactive student.” (participant 20; double-coded as personal benefit)

"I know when I was younger, I didn't like when a teacher would answer my question with another question. After teaching, I have a better understanding of the critical thinking skills that teachers are trying to develop in their students. I found this to be a good approach, as the students would take the time to figure it out for themselves." (participant 23; doublecoded as perspective on teaching)

\section{Theme 3: Applications to Future}

"I want to be present in the lives of students pursuing degrees, and show them the importance of this as I see it, and help them learn in order to perpetuate the cycle of successful, supportive, and helpful clinicians in our field.” (participant 3)

"My experience as an instructional intern gave me the opportunity to give back. As a student in the CSD program, instructional interns have been a vital component to my learning. They have been a helpful resource and could often provide an alternative explanation of course material. This experience allowed me to be in that role." (participant 14)

"I recognize I am pursuing a career in a teaching profession. Whether as a student working with my peers, as a clinician working with a client, or as a professional working with a client, family members, or co-workers, I will always be in a position to teach people. Doing so will be one of the most challenging and rewarding pieces of this field as I will have to comprehend the material and be able to convey it to a wide audience of individuals to be useful.” (participant 25)

"This overlaps with my experience as an undergraduate clinician this semester, because essentially I was teaching a skill during my therapy sessions. The difference between my clinic and II experiences was the material I was teaching." (participant 23)

"I realized explaining concepts to students is similar to the professional field. I have to use the correct terminology and clarify any misconceptions to other professionals, family members, and especially to the client. This communicative skill can literally be applied to any circumstance and person.” (participant 30) 
"The term instructor does not only pertain to a teacher, but also parent, therapist, clinician, etc. I can apply what I have learned in my experience as an Instructional Intern to my future experiences in the clinic. I will be teaching new techniques and strategies to clients, just as I have taught new information to the students in Phonetics.” (participant 1)

"To know there are teachers out there who care so much about their student's success, shows me how important it is for me to do the same. I know I now can make a difference in the success of someone's life. Whether I become a teacher or Speech-Language Pathologist, I've learned it's not just a career; it's making a difference in people's lives which is really what's important.” (participant 6)

\section{Theme 4: Personal Benefits}

"I learned that being a professor is a profession that would not be for me.” (participant 8)

"Additionally, reviewing this information helped me make the decision to apply solely to audiology programs.” (participant 9)

"My leadership skills were enhanced this semester, and I now feel more comfortable and confident speaking in front of and teaching others.” (participant 13)

"This not only enhanced my leadership skills, but it also enhanced my critical thinking skills. I had to read the chapter and think deeper in order to create an effective discussion board that would go along with the chapter as well as what their future profession might be.” (participant 19)

“Overall, this experience has made me a better student. I have gained a deeper appreciation for information presented to us as students and noted how important it is to be a proactive student.” (participant 20)

"The most important piece I am taking away from this experience is the extra knowledge I have gained by hearing and seeing the information from this class being taught for a second time. I learned about the voice and disorders that can occur with it when I first took this class. By hearing the information once again, it solidified my knowledge in this area of our profession.” (participant 21)

\section{Theme 5: Challenges}

"I found that both motivating the learner (student or client), and getting the learners to seek the intrinsic motivation on their own was the biggest problem I encountered. In reaction to this issue, I found that offering optional practice just isn't enough to push the students toward success. A reward system, either class points or extra credit, seemed to be the only 
way to truly get all students to engage in an activity." (participant 1; double-coded as perspective on learning)

"After a semester as Instructional Intern for CSD 150: Introduction to Communication Sciences and Disorders I have an entirely new respect for teachers of all professions. Because college does not entail 'holding the students hand' it is simple to see how frustrating it actually becomes when students do not take the initiative and responsibility for their own education.” (participant 24; double-coded with perspectives on teaching)

"I think a change to my perspective as a teacher, is that explaining concepts is more difficult than you think as a student learning. During some review sessions for exams, students would ask us specific questions about material and it was hard to come up with good explanations.” (participant 15; double-coded as perspective on teaching)

"One of the other main learning points for me was the amount of work it takes to be a professor. There are so many aspects that need to be covered in order for the course to be successful. Professors have to prepare for class, get class materials together, grade papers, upload D2L documents, answer questions, create quizzes and exams, and be ready for anything else that comes up.” (participant 8, double-coded as perspective on teaching)

\section{References}

Adler, P.A. (1993). Personalizing mass education: The assistant teaching assistant (ATA) program. Teaching Sociology 21, 172-176. doi:10.2307/1318639

ASHA. (2002). Crisis in the discipline: a plan for reshaping our future. American SpeechLanguage-Hearing Association and Council of Academic Programs in Communication Sciences and Disorders: Report of the joint ad hoc committee on the shortage of PhD students and faculty in communication sciences and disorders.

ASHA. (1985). Position Statement: Clinical supervision in speech-language pathology and audiology. http://www.asha.org/policy/PS1985-00220/

Anderson-Darling, C., \& Earhart, E.M. (1990). A model for preparing graduate students as educators. Family Relations, 39, 341-348. doi:10.2307/584882

Baldwin, T.T., \& Ford, J.K. (1988). Transfer of training: A review and directions for future research. Personnel Psychology, 41, 63-105. doi:10.1111/j.1744-6570.1988.tb00632.x

Birch, J.B., \& Morgan, J.P. (2005). TA training at Virginia Tech: A stepwise progression. The American Statistician, 59(1), 14-18. doi:10.1198/000313005X24174 
Cici, J.C., \& Ruiz, A. (1993). Transfer, abstractness, and intelligence. In D.K. Detterman \& R.J. Sternberg, (Eds.), Transfer on trial: Intelligence, cognition, and instruction (pp. 168-191). Norwood, NJ: Ablex.

Detterman, D. K. (1993). The case for the prosecution: transfer as an epiphenomenon. In D.K.Detterman \& R.J. Sternberg, (Eds.) (1993). Transfer on trial: Intelligence, conclusion cognition, and instruction (pp. 1-24). Norwood, NJ: Ablex.

Fingerson, L., \& Culley, A.B. (2001). Collaborators in teaching and learning: Undergraduate teaching assistants in the classroom. Teaching Sociology 29, 299-315. doi:10.2307/1319189

Froelich, A.G., Duckworth, W.M., \& Stephenson, W.R. (2005). Training statistics teachers at Iowa State University. The American Statistician, 59 (1), 8-10. doi:10.1198/000313005X24138

Gaia, C.A., Corts, D.P., Tatum, H.E., \& Allen, J. (2003). The GTA Mentoring Program: An interdisciplinary approach to developing future faculty as teacher-scholars. College Teaching, 51(2), 61-65. doi:10.1080/87567550309596413

Green, J.L. (2010). Teaching highs and lows: Exploring university teaching assistants' experiences. Statistics Education Research Journal, 9 (2), 108-122.

Harland, T. (2001). Pre-service teacher education for university lectures: the academic apprentice. Journal of Education for Teaching, 27(3), 269-276. doi:10.1080/02607470120091597

Muzaka, V. (2009). The niche of Graduate Teaching Assistants (GTAs): Perceptions and reflections. Teaching in Higher Education, 14 (1), 1-12. doi:10.1080/13562510802602400

Peterson, E. (1990). Helping TAs to teach holistically. Anthropology \& Education Quarterly, 21(2), 179-185. doi:10.1525/aeq.1990.21.2.04x0260z

Shannon, D.M., Twale, D.J., \& Moore, M.S. (1998). TA Teaching Effectiveness: the impact of training and teaching experience. The Journal of Higher Education, 69(4), 440-466. doi:10.2307/2649274

Singley, M. K., \& Anderson, J. (1989). The transfer of cognitive skill. Cambridge, MA: Harvard University Press.

Socha, T.J. (1998). Developing an undergraduate teaching assistant program in communication: Values, curriculum, and preliminary assessment. Journal of the Association for Communication Administration, 27, 77-83.

Strauss, A., \& Corbin, J. (1990). Basics of qualitative research: Grounded theory procedures and techniques. London: Sage.

Tulane, S., \& Beckert, T.E. (2011). Perceived utility and knowledge of graduate teaching assistants. Journal of the Scholarship of Teaching and Learning, 11 (4), 44-55.

Wallace, R.A. (1974). An alternative to assembly-line education: Undergraduate teaching assistants. Teaching Sociology, 2(1), 3-14. doi:10.2307/1317240 
Hemmerich, A. L., Hoepner, J. K., \& Samelson, V. M.

Yang, Y-T.C. (2008). A catalyst for teaching critical thinking in a large university class in Taiwan: Asynchronous online discussions with the facilitation of teaching assistants. Education Technology Research and Development, 56, 241-264.

doi:10.1007/s11423-007-9054-5 